\title{
Inhibition of the expression of aquaporin-1 by RNA interference in pulmonary epithelial cells and its effects on water transport
}

\author{
QIUYUE ZHANG ${ }^{1}$, JIANHUA FU ${ }^{2}$ and XINDONG XUE ${ }^{2}$ \\ ${ }^{1}$ Department of Pediatrics, The First Affiliated Hospital of Harbin Medical University, Harbin, Heilongjiang 150001; \\ ${ }^{2}$ Department of Pediatrics, China Medical University Affiliated to Shengjing Hospital, Shenyang, Liaoning 110004, P.R. China
}

Received December 18, 2014; Accepted September 16, 2015

DOI: $10.3892 / \mathrm{mmr} .2015 .4519$

\begin{abstract}
In the present study, the effect of aquaporin-1 (AQP1) on fluid transportation in pulmonary epithelial cells, and the role of AQP1 in alveolar fluid clearance were investigated to provide an experimental foundation to elucidate the pathogenesis of hyperoxic lung edema. An siRNA transfection technique was used to silence AQP1 in the A549 cell line. The transfected cells were randomized into a hyperoxia exposure and an air control group, with a negative control group set for each group. Cell volume was determined using flow cytometry, and Pf values were used to determine osmotic water permeability. Cell volume was found to be reduced in the AQP1-silenced A549 cells, compared with the negative control group $72 \mathrm{~h}$ following air exposure. In addition, cell volume was reduced in the AQP1-silenced A549 cells, compared with the negative control group 48 and $72 \mathrm{~h}$ following hyperoxia exposure. The osmotic water permeability of the AQP1-silenced cells was reduced in the air control and hyperoxia exposure groups, compared with the negative control group 48 and $72 \mathrm{~h}$ following exposure. The volume and cell membrane osmotic water permeability of the A549 cells were reduced, compared with those in the control group following AQP1-silencing, which indicated that the downregulation of AQP1 impedes extracellular to intracellular fluid transportation. Therefore, the disturbance in alveolar fluid clearance resulting from the downregulation of AQP1 following hyperoxia exposure may be one of the key mechanisms responsible for hyperoxic lung edema.
\end{abstract}

\section{Introduction}

High oxygen levels may cause bronchial pulmonary hypoplasia, which has a prevalence of $1.26 \%$ in China (1). It has been suggested that alterations in the expression levels of aquaporin-1 (AQP1) may be involved in the rapid transportation of alveolar fluid in the early stages of pulmonary injury, due to

Correspondence to: Dr Qiuyue Zhang, Department of Pediatrics, The First Affiliated Hospital of Harbin Medical University, 23 Youzheng, Harbin, Heilongjiang 150001, P.R. China E-mail: qiuyuezhangcn@126.com

Key words: A549 cell, aquaporin-1, hyperoxia, RNA interference previous observations that the expression and activity levels of AQP1 are reduced in multiple pulmonary injuries (2-4).

The present study aimed to investigate whether high levels of oxygen affect the expression levels of AQP1 in newborn rat lung epithelial cells, which may be one of the reasons for high oxygen-induced pulmonary edema (5). At present, there is no direct experimental evidence to support the definite involvement of a downregulation in AQP1 in lung edema in newborn rats exposed to hyperoxia, due to the fact that sodium-potassium ATPase and fluid transportation systems in addition to AQP are also present in lung tissues (6). In the present study, the AQP1 gene was silenced using an RNA interference (RNAi) technique in human pulmonary adenocarcinoma A549 cells. This was performed in order to verify the direct correlation between AQP1 and cell fluid transportation at a cellular level, in addition to further elucidating its association with the pathogenesis of lung edema during hyperoxic pulmonary injury.

Oxygen is crucial for human beings, but long-term inhalation of a high concentration of oxygen can lead to lung injury in premature babies with bronchial pulmonary hypoplasia (BPD). The pathogenesis of BPD is not entirely clear, however, the pathological process includes early pulmonary edema and late pulmonary fibrosis.

\section{Materials and methods}

Cell culture. Human pulmonary adenocarcinoma A549 cells (Central Laboratory, China Medical University Affiliated Shenjing Hospital, Shenyang, China) were cultured in RPMI 1640 culture medium (Sigma-Aldrich, St. Louis, MO, USA) containing 10\% fetal bovine serum (FBS; Clark, Seabrook, MD, USA) at $37^{\circ} \mathrm{C}$ and $5 \% \mathrm{CO}_{2}$ in a cell incubator. The cell medium was refreshed every $1-2$ days. Trypsin $(0.25 \%$; Merck Millipore, Darmstadt, Germany) was used to digest and passage the cells for 5-10 min every 2-3 days.

Experimental group assignment and intervention. The A549 cells were randomized into two groups: Air group and hyperoxia group. Each group was further divided into a gene silencing group and negative control group. The cells in the air group were cultured in a normal cell incubator (oxygen volume fraction=0.21) and the cells in the hyperoxia group were cultured in a hyperoxic incubator (oxygen volume fraction=0.90) for 24 , 48 and $72 \mathrm{~h}$ prior to detection. 
Preparation of the AQP1 gene-silencing cell model. To silence the gene expression of AQP1, AQP1-siRNA transient transfection using ON-TARGETplus Smart Pool siRNA (Thermo Fisher Scientific, Inc., Waltham, MA, USA) and DharmaFECT 1 (T-2001-01; Thermo Fisher Scientific, Inc.) transfection reagent was performed. The potential sequences in the target mRNAs of AQP1, beginning with an AA dinucleotide were identified and compared with the human genome database using the Basic Local Alignment Search Tool (BLAST; http://blast.ncbi. nlm.nih.gov/Blast.cgi). Any target sequences with base pairs of homology to other coding sequences were eliminated from consideration. In total, four pairs of sequences were designed and synthesized (Sangon Biotech Co., Ltd., Shanghai, China), as follows ( $\left.5^{\prime}-3^{\prime}\right)$ : siRNA1, 5'-GAACUCACUUGGCCG AAAU-3'; siRNA2, 5'-CCGUUAACCAUGUCGUGAA-3'; siRNA3, 5'-CCCAAAUAGAGGAGGCUUG-3'; and siRNA4, 5'-UGACGUGUGUGUUUAUUAA-3'. Negative siRNA sequences were used as negative controls. For knockdown of the expression of AQP1, the A549 cells were plated at a concentration of $4 \times 10^{5}$ cells/well in 6-well plates and incubated in antibiotic-free media overnight. A total of $100 \mu 1$ siRNA ( $2 \mu \mathrm{mol} / \mathrm{l})$ and $2 \mu \mathrm{l}$ DharmaFECT were diluted with $100 \mu \mathrm{l}$ and $198 \mu 1$ serum-free medium, respectively, and set aside for $5 \mathrm{~min}$ at room temperature. The two dilutions were mixed and left for $20 \mathrm{~min}$ at room temperature, prior to the addition of 1,600 $\mu 1$ antibiotic-free and serum-free complete media, to produce a total volume of $2 \mathrm{ml}$ transfection medium. The cells were overlaid with the transfection medium and were incubated for $6 \mathrm{~h}$ at $37^{\circ} \mathrm{C}$. The cells were then washed with phosphate-buffered saline (PBS) and cultivated in RPMI 1640 medium containing $10 \% \mathrm{FBS}$. At 48 and $72 \mathrm{~h}$ post-transfection, the cells were harvested and stored at $-80^{\circ} \mathrm{C}$ for further analysis.

Reverse transcription-quantitative polymerase chain reaction $(R T-q P C R)$. The A549 cells were harvested by centrifugation at $111.8 \mathrm{x} \mathrm{g}$ at $4^{\circ} \mathrm{C}$ for $5 \mathrm{~min}$, and were randomized into a gene silencing and negative control group ( $1 \times 10^{9}$ cells/group), and were cultured in a cell incubator (oxygen volume fraction $=0.21$ ) for $48 \mathrm{~h}$. Briefly, total RNA was extracted from the harvested cells using an acid guanidinium-phenol-chloroform method (TRIzol $^{\oplus}$; Invitrogen; Thermo Fisher Scientific, Inc.). The total RNA was reverse transcribed into cDNA in a $20 \mu \mathrm{l}$ reaction containing $8 \mu 1$ RNA, $2 \mu 1$ oligo(dT)15 (Tiangen Biotech Co., Ltd., Beijing, China), $2 \mu \mathrm{ldNTP}$ (2.5 mM; Tiangen Biotech Co., Ltd.), $1.5 \mu 1$ RNase-free $\mathrm{ddH}_{2} \mathrm{O}, 4 \mu 1$ 5X First-Strand Buffer (Tiangen Biotech Co., Ltd.), $1 \mu \mathrm{l}(0.1 \mathrm{M})$ DTT (Tiangen Biotech Co., Ltd.), $0.5 \mu 1$ RNasin (Tiangen Biotech Co., Ltd.) and $1 \mu 1$ (200 M) TIANScript M-MLV (Tiangen Biotech Co., Ltd.). The mixture was incubated for $50 \mathrm{~min}$ at $42^{\circ} \mathrm{C}$ and the reaction was terminated by heating to $95^{\circ} \mathrm{C}$ for $5 \mathrm{~min}$. The cDNA synthesized by reverse transcription was used as templates for quantitative fluorescent analysis using a fluorescent quantitator (Exicycler $^{\mathrm{TM}}$ 96; Bioneer Corporation, Daejeon, Korea). An equal volume of cDNA was amplified in a reaction mixture consisting of $10 \mu \mathrm{l}$ Taq 2X PCR Master Mix (Tiangen Biotech Co.,Ltd.), $7.5 \mu 1 \mathrm{ddH}_{2} \mathrm{O}, 9 \mu \mathrm{l}$ SYBR Green (Tiangen Biotech Co., Ltd.), $1.5 \mu \mathrm{l}$ cDNA and $1 \mu \mathrm{l}$ gene-specific forward and reverse AQP1 primers. The primer sequences (Sangon Biotech Co., Ltd.) were as follows: Forward, 5'-ACCCGCAACTTCTCA AAC-3' and reverse, 5'-CAGGTCATACTCCTCCACTT-3'.
The initial denaturation was at $95^{\circ} \mathrm{C}$ for $10 \mathrm{~min}$, followed by 40 cycles of $95^{\circ} \mathrm{C}$ for $10 \mathrm{sec}, 55^{\circ} \mathrm{C}$ for $30 \mathrm{sec}$ and $68^{\circ} \mathrm{C}$ for $40 \mathrm{sec}$. Melt curves were used to determine the formation of a single product. The quantification cycle $(\mathrm{Cq})$ was recorded for each sample to reflect the mRNA expression levels. The $\mathrm{Cq}$ values and data were analyzed using the $2^{-\Delta \Delta C q}$ method (7). The hGAPDH gene (forward, GAAGGTCGGAGTCAACGGAT, and reverse, CCTGGAAGATGGTGATGGGAT) was used as an internal control. All experiments were repeated three times.

Western blot analysis. Total protein was extracted from the cells using radioimmunoprecipitation assay buffer (Beyotime Institute of Biotechnology, Shanghai, China), and were quantified using a standard curve. The cells were randomized into a gene silencing and a negative control group and were cultured in a cell incubator (oxygen volume fraction $=0.21$ ) for $72 \mathrm{~h}$. Proteins were extracted from the harvested cells for quantitation. The proteins $(9 \mu \mathrm{g})$ were loaded onto a 5\% SDS-PAGE gel (Beyotime Institute of Biotechnology) for electrophoresis and transferred onto cellulose membranes (Merck Millipore) prior to blocking in buffer containing $5 \%$ non-fat milk powder for $2 \mathrm{~h}$. The membrane was incubated with mouse anti-human monoclonal AQP1 primary antibody (cat. no. sc25287; 1:400; Santa Cruz Biotechnology, Inc., Danvers, MA, USA) at $37^{\circ} \mathrm{C}$ for $1 \mathrm{~h}$, and washed with Tris-buffered saline with Tween 20 prior to hybridization with alkaline phosphatase-labeled goat anti-mouse monoclonal secondary antibody (cat. no. A0216; 1:10,000; Beyotime Institute of Biotechnology) at $37^{\circ} \mathrm{C}$ for $40 \mathrm{~min}$. Subsequently, images of the film (WD-9413B; Beijng Liuyi Biotechnology Co., Ltd., Beijing, China) were captured using an imaging system (WD-9413B; Beijing Six One Company) following electrochemiluminescence (Merck Millipore) exposure, and analyzed using Exicycler 96 (Bioneer Corporation). The results were presented as the relative grey value of the AQP1 band/grey value of the GAPDH band.

Determination of cell volume following AQPI-silencing. The cells in each group were cultured for 24,48 and $72 \mathrm{~h}$ prior to washing with PBS and digesting with $0.25 \%$ trypsin for 5-10 min. Equal volumes of Dulbecco's modified Eagle's medium containing $10 \%$ FBS were used to terminate digestion. Subsequently, the cells were centrifuged at $75.55 \mathrm{x}$ g for $5 \mathrm{~min}$ at $4^{\circ} \mathrm{C}$ and washed twice with PBS. The resuspended cells were agitated to form a homogenous single cell suspension and were adjusted to $10^{9}$ cells/l. Subsequently, 10,000 cells were obtained from $0.5 \mathrm{ml}$ cell suspension and analyzed using flow cytometry (FACSCalibur; BD Biosciences, Franklin Lakes, CA, USA), and the average intensity of forward scatter (FSC) was calculated (8). Light scattering was generated when a single line of cells ejected from the nozzle of the flow cytometer was exposed to laser irradiation. The channel numbers of the average intensity of FSC were used to represent cell volume, as cell volume increased with the intensity of scattering light, or FSC intensity was proportional to cell volume.

Determination of cell osmotic fluid permeability (Pf) following gene silencing. The osmotic $\mathrm{Pf}$ of the cell represents the water trans-membrane transport capability driven by an osmotic gradient, and can directly reflect cell osmotic water transport function (9). 
The Pf values were calculated using the following formula: $\mathrm{Pf}=\left[\mathrm{V}_{0} \mathrm{xd}\left(\mathrm{V} / \mathrm{V}_{0}\right) / \mathrm{dt}\right] /\left[\mathrm{SxV}_{\mathrm{W}} \mathrm{x}\left(\mathrm{Osm}_{\mathrm{in}}-\mathrm{Osm}_{\text {out }}\right)\right]$; $\mathrm{V}=4 / 3 \times\left(\right.$ area) $\mathrm{x}(\operatorname{area} / \pi)^{1 / 2}$.

The area denotes the cell surface area, Osm denotes osmotic pressure, $\mathrm{Osm}_{\text {in }}$ denotes intracellular osmotic pressure, $\mathrm{Osm}_{\text {out }}$ denotes extracellular osmotic pressure. The Pf value was determined by the initial $\mathrm{V} / \mathrm{V}_{0}$ time course ratio, $\mathrm{d}\left(\mathrm{V} / \mathrm{V}_{0}\right) / \mathrm{dt}$; initial cell volume, $\mathrm{V}_{0}\left(\mathrm{~cm}^{3}\right)$; initial cell surface area, $\mathrm{S}\left(\mathrm{cm}^{2}\right)$; and water molar volume, $\mathrm{V}_{\mathrm{W}}\left(18 \mathrm{~mol} / \mathrm{cm}^{3}\right)$.

The cell group assignment and harvesting methods were, as described above. The cells were transferred between PBS of $200 \mathrm{mOsm}$ and $70 \mathrm{mOsm}$ (diluted with deionized water) prior to microscopic image capture (IX53; Olympus Corporation, Tokyo, Japan) every $30 \mathrm{sec}$ for $3 \mathrm{~min}$. The cell area was calculated using Image-Pro 6.0 software (Media Cybernetics, Inc., Rockville, MD, USA) for imaging analysis. The cell volume and Pf values were calculated using the above formula.

Statistical analysis. SPSS software, version 13.0 (SPSS, Inc., Chicago, IL, USA) was used for statistical analysis. The independent $\mathrm{t}$-test was used for comparisons of means between two samples. $\mathrm{P}<0.05$ was considered to indicate a statistically significant difference.

\section{Results}

mRNA expression of AQP1 is decreased in A549 cells following gene silencing. The RT-qPCR analysis performed in the present study revealed a significant downregulation in the mRNA expression of AQP1 in the gene silencing group $(\mathrm{P}<0.01)$, when compared with that of the negative control group. The AQP1 mRNA inhibition rate was $75.5 \%$ (Fig. 1).

Protein expression of AQP1 decreases following A549 cell gene silencing. The results of the western blotting revealed a significant downregulation in the protein expression of AQP1 in the gene silencing group $(\mathrm{P}<0.01)$, compared with that of the negative control group. The inhibition rate of AQP1 protein was $81.5 \%$ (Fig. 2).

Changes in A549 cell volume following gene silencing. No significant difference in cell volume was observed at 24 or $48 \mathrm{~h}$ between the gene silencing group and negative control group when exposed to air $(\mathrm{P}>0.05)$, whereas the cell volume in the gene silencing group was significantly reduced, compared with that in the negative control group at $72 \mathrm{~h}(\mathrm{P}<0.01$; Fig. 3$)$.

Cell volume in the gene silencing group exposed to hyperoxia was significantly reduced, compared with the negative control group at 48 and $72 \mathrm{~h}(\mathrm{P}<0.01)$, although no significant differences in cell volume were observed at $24 \mathrm{~h}(\mathrm{P}>0.05$; Fig. 4).

Osmotic Pf following gene silencing. No significant differences were observed in the Pf values between the gene silencing group and negative control group exposed to air at $24 \mathrm{~h}(\mathrm{P}>0.05)$. However, the Pf values of the gene silencing group were significantly reduced, compared with those of the negative control group at 48 and $72 \mathrm{~h}(\mathrm{P}<0.01$, Fig. 5).

No significant difference were observed in the Pf values between the gene silencing group and negative control group

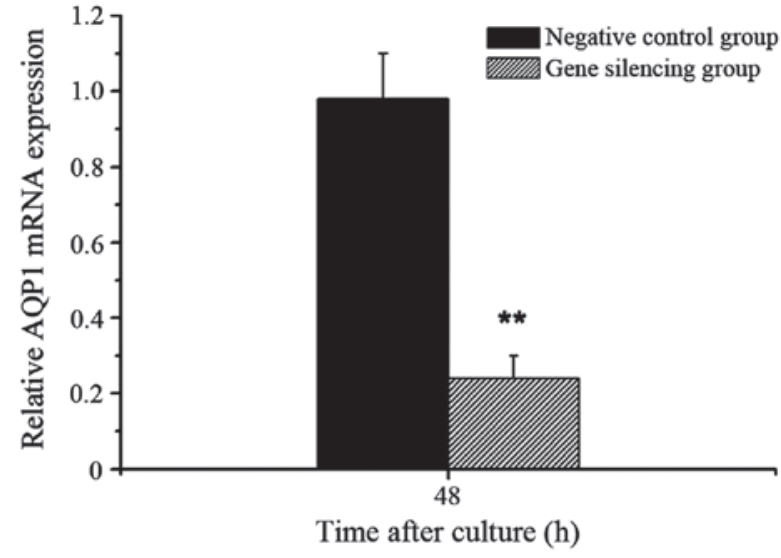

Figure 1. Changes in the relative mRNA expression levels of AQP1 subsequent to AQP1 gene silencing. The results of the RT-qPCR analysis demonstrated that the A549 cells were successfully transfected by AQP1-siRNA. For knockdown of the expression of AQP1, four pairs of sequences were used in the gene silencing group. Negative siRNA sequences were used as controls in the negative control group. At $48 \mathrm{~h}$ following transfection, the cells were harvested and analyzed. Subsequent RT-qPCR indicated that the the AQP1 mRNA inhibition rate was $75.5 \%$. Data are presented as means \pm standard deviation. ${ }^{* *} \mathrm{P}<0.01$, vs. negative control group. AQP1, aquaporin-1; RT-qPCR, reverse transcription-quantitative polymerase chain reaction.

A

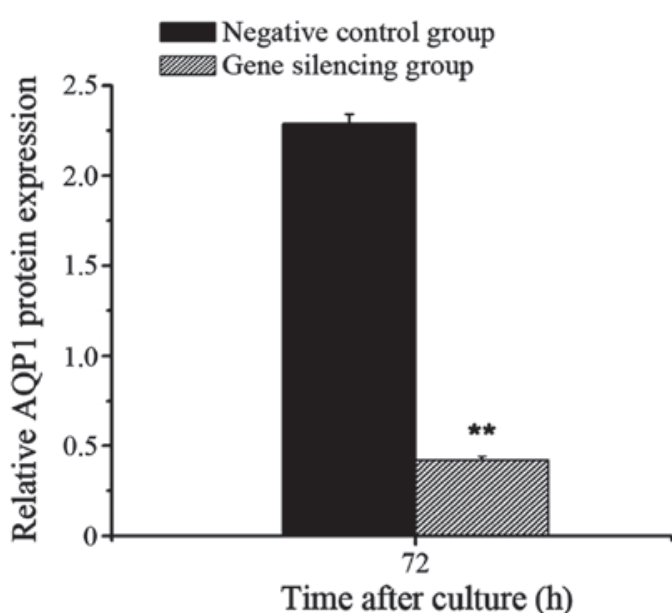

B

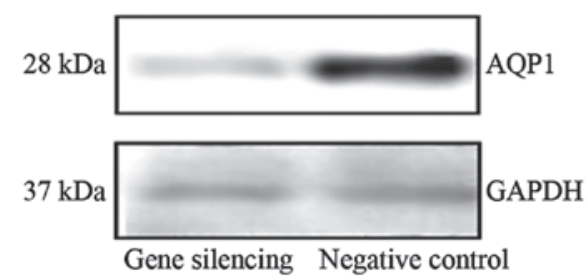

Figure 2. Protein expression of AQP1. (A) Changes in the relative protein expression levels of AQP1 subsequent to gene silencing. Data are presented as means \pm standard deviation. ${ }^{* *} \mathrm{P}<0.01$, vs. negative control group. (B) Detection of the protein expression of AQP1 following RNA interference using western blotting. AQP1, aquaporin-1

exposed to hyperoxia at $24 \mathrm{~h}(\mathrm{P}>0.05)$, however, the $\mathrm{Pf}$ values of the gene silencing group were reduced, compared with those of the negative control group at 48 and $72 \mathrm{~h}(\mathrm{P}<0.01$; Fig. 6$)$. 
A

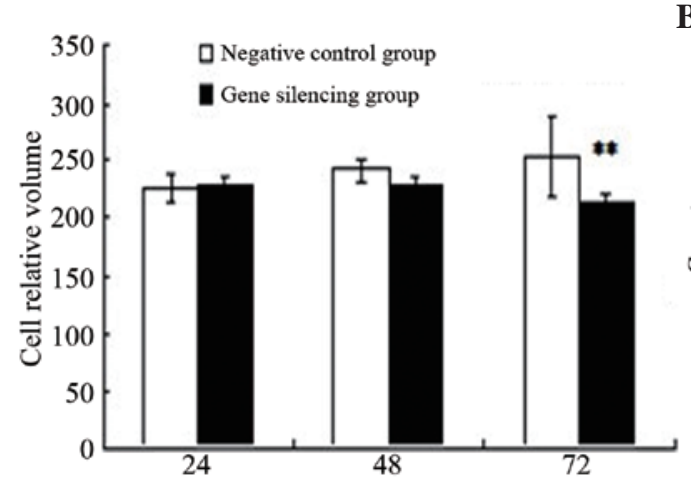

Time (h)

C

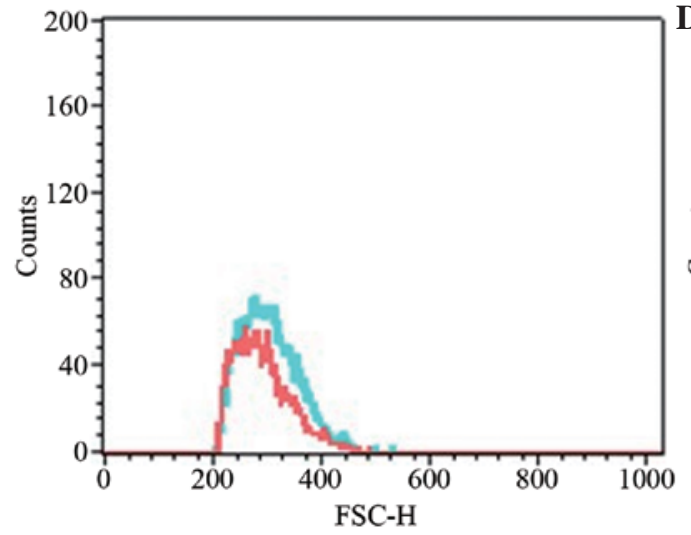

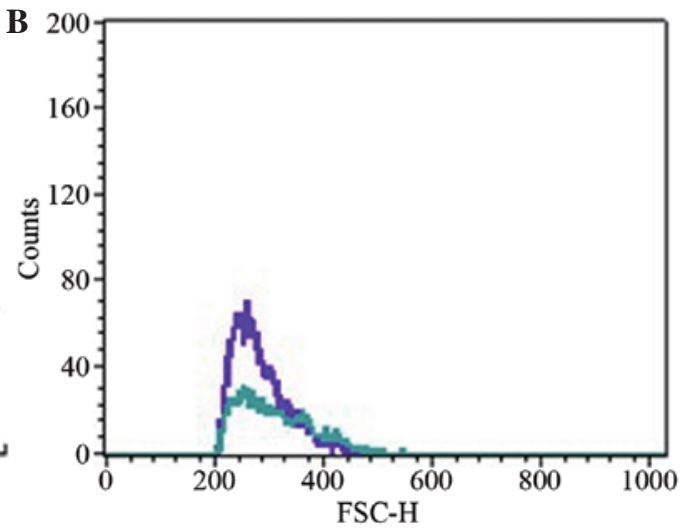

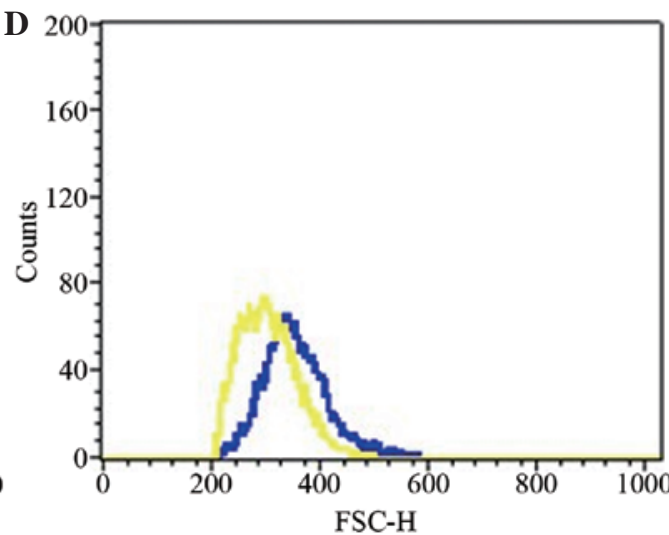

Figure 3. Changes in cell volume. (A) Cell volume of the two groups following gene silencing. Data are presented as means \pm standard deviation. "** $\mathrm{P}<0.01$, vs. negative control group. Determination cell volumes in the AQP1 gene-silencing group exposed to air were determined using flow cytometry at (B) $24 \mathrm{~h}$ (purple, silencing group; blue, negative control group), (C) $48 \mathrm{~h}$ (pink, silencing group; blue, negative control group) and (D) $72 \mathrm{~h}$ (yellow, silencing group; blue, negative control group) following transfection. AQP1, aquaporin-1; FSC-H, forward scatter height.

A

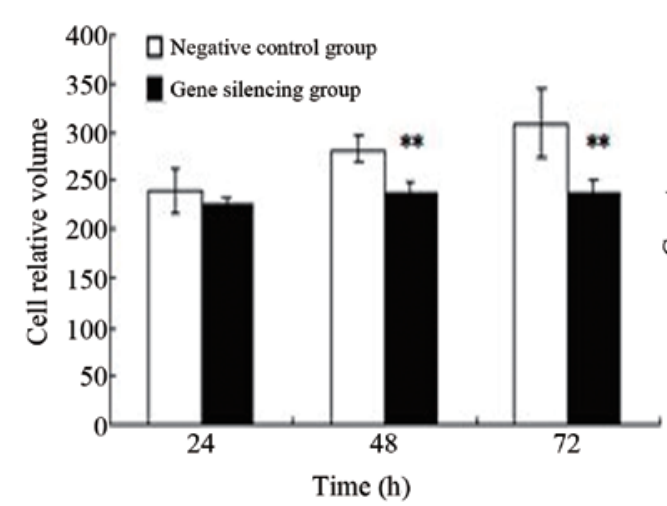

C

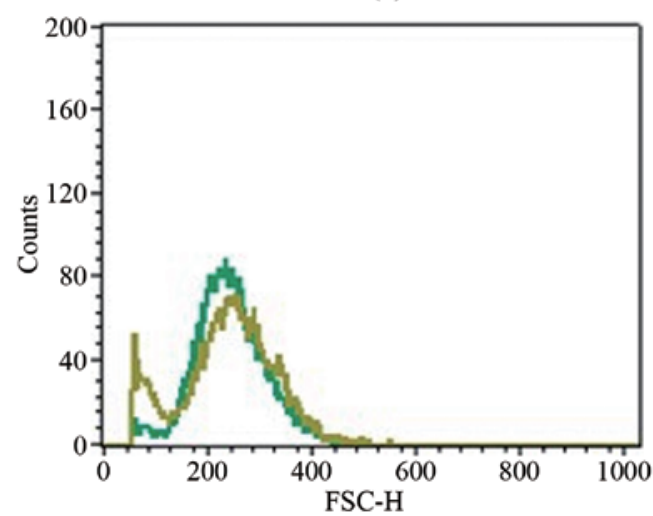

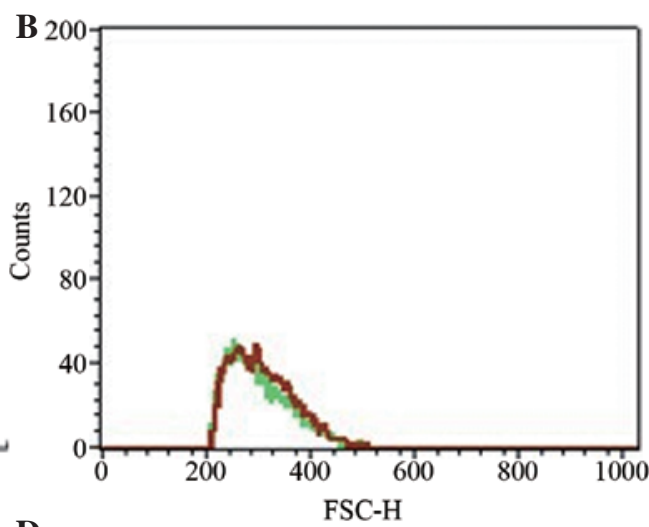

D

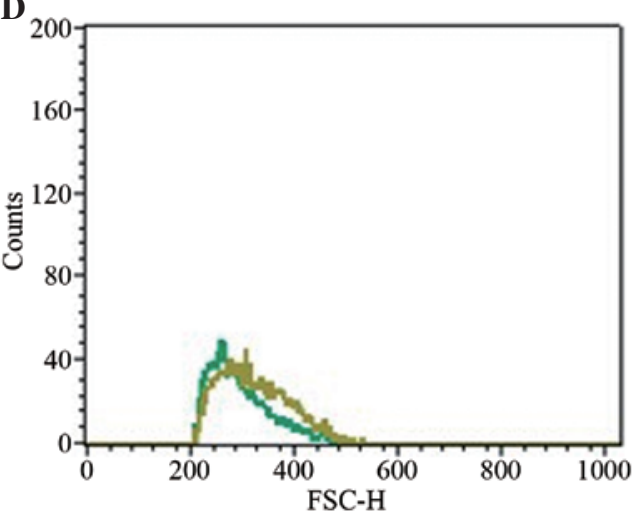

Figure 4. Changes in cell volume. (A) Cell volumes in the two hyperoxic groups following gene silencing. Data are presented as means \pm standard deviation. ${ }^{* *} \mathrm{P}<0.01$, vs. negative control group. Determination of cell volumes in the AQP1 gene silencing group exposed to hyperoxia were determined using flow cytometry (B) $24 \mathrm{~h}$ (green, gene silencing group; red, negative control group), (C) $48 \mathrm{~h}$ (dark green, gene silencing group; light green, negative control group) and (D) $72 \mathrm{~h}$ (dark green, gene silencing group; light green, negative control group) following transfection. AQP1, aquaporin-1; FSC-H, forward scatter height. 


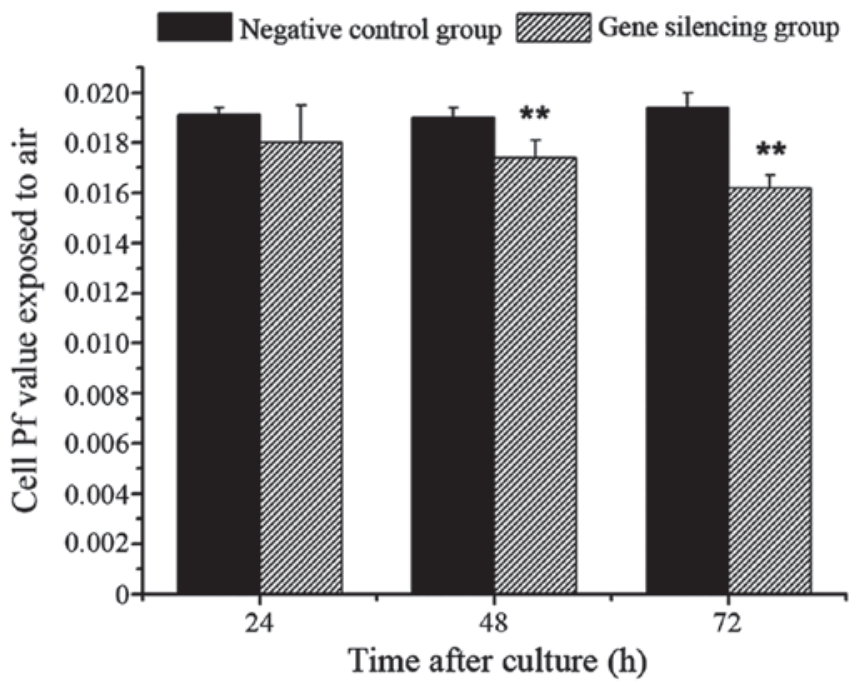

Figure 5. Cell Pf value of the two groups exposed to air following aquaporin-1 gene silencing. Data are presented as means \pm standard deviation. ${ }^{* *} \mathrm{P}<0.01$, vs. negative control group. Pf, fluid permeability.

\section{Discussion}

The AQP family is a group of small, hydrophobic trans-membrane proteins, of which the monomers are 26-34 kDa in size. AQPs are selectively permeable to water at a velocity of $100-200 \times 10^{-6} \mathrm{~m} \cdot \mathrm{s}^{-1}$, which is $10^{9}$-fold higher than normal diffusion velocity (10). At present, 13 AQPs (AQP0-12) have been identified, which are observed in all life forms, including humans, animals, plants, bacteria and yeasts (11). Currently, the expression of six AQPs, including AQP1, AQP3, AQP4, AQP5, AQP8 and AQP9, have been identified in lung tissues (12).

AQPs are important in maintaining the water equilibrium between alveoli and capillaries. AQP1 is expressed in lung endothelial and epithelial cells and regulates water transport, being important in a number of edema-associated lung diseases $(13,14)$. Lung injury resulting from multiple factors is accompanied by reductions in the expression and activities of AQP1. Towne et al (14) demonstrated that adenovirus infection resulted in pneumonia, pulmonary edema and downregulation of AQP1 in lung tissues. It has also been reported that the transmembrane fluid transportation capacity mediated by AQP in lung tissues is reduced by $43 \%$ in mice following exposure to $100 \%$ oxygen for 5 days (15), with reductions in the expression or activity of AQP1 observed. The mRNA expression levels of AQP1 and AQP4 have been found to be downregulated in allergen-induced mouse models of asthma (16). In addition, reduced expression levels of lung AQP1 and AQP5 may be associated with the development of pulmonary edema and increased severity of lung injury and pulmonary edema, which provides an additional mechanism for pancreatitis-associated lung injury (17). It has also been observed that impaired alveolar fluid clearance rate is the predominant manifestation in lipopolysaccharide-induced acute lung injury, and symptoms can be relieved through dopamine-induced upregulation in the expression levels of AQP1 and AQP5, and subsequent enhancement of alveolar fluid reabsorption (18). Qi et al (2) reported that limb ischemia-reperfusion-induced

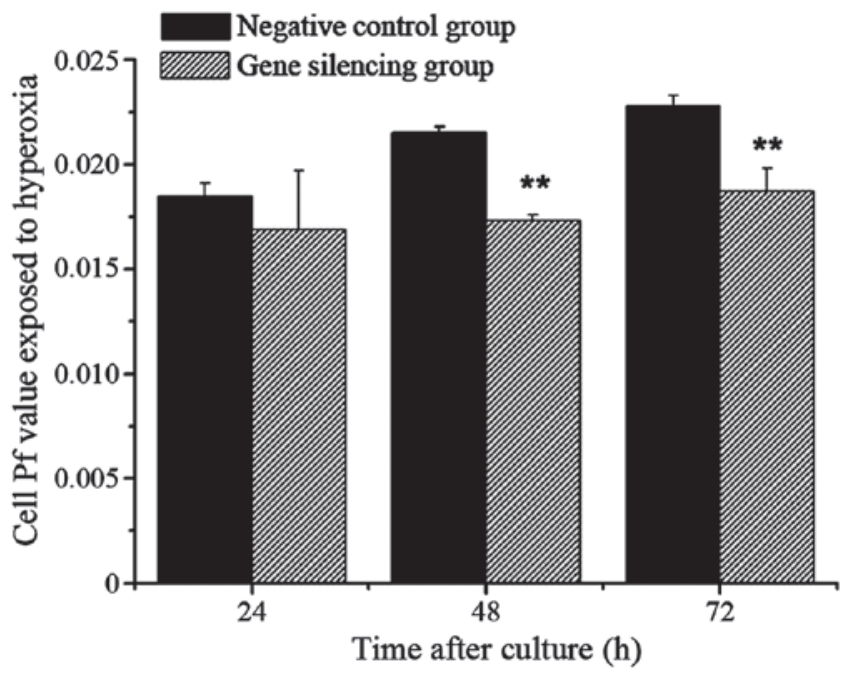

Figure 6. Cell Pf valued of the two groups exposed to hyperoxia following aquaporin-1 gene silencing. Data are presented as means \pm standard deviation. ${ }^{* *} \mathrm{P}<0.01$, vs, negative control group. $\mathrm{Pf}$, fluid permeability.

lung injury was accompanied by upregulation of the toll-like receptor 4-myeloid differentiation primary response protein 88-nuclear factor $\kappa \mathrm{B}$ pathway and downregulation of the expression of AQP1/AQP5. Ventilation with a large tidal volume results in the production of inflammatory mediators and the downregulation of AQP1, which can be attenuated by the inhibition of cyclooxygenase-2 (19). Gao et al (20) observed that the Chinese medicine, Qing Yi Tang, protects the lungs from injury induced by severe acute pancreatitis via the upregulation of AQP1, which suppresses the expression of tumor necrosis factor $\alpha$.

Experiments have revealed that, compared with wild-type mice, water permeability between the alveoli and the capillaries in AQP1-knockout mice was reduced 10-fold (21). King et al (22) reported that the airway wall was unchanged following saline perfusion in the congenital absence of AQP1, whereas the wall was thickened by $50 \%$ in normal airways.

However, upregulation in the expression of AQP1 in lung injury has been observed in previous studies. In a study by Li et al (23), results from RT-qPCR and western blotting indicated that intratracheal installation of seawater upregulated the mRNA and protein levels of AQP1 and AQP5 in lung tissues. Lai et al (24) observed that inflammatory factors were able to stimulate the expression of AQP1 in cell models, and Song et al (25) used transgenic technology and observed that AQP1-, AQP4- and AQP5-knockout in mice had no effects on pulmonary edema or pleural effusion formation, or on the clearance of lung fluid in acute lung injury of neonatal mice. The underlying pathology of early phase pulmonary edema in hyperoxic lung injury had been confirmed (26). The present study hypothesized that hyperoxia results in the downregulation of AQP1 on the type II alveolar epithelial cell (AEC-II) membrane, affecting alveolar water transport and clearance. In order to confirm this, an RNAi technique was used to determine the roles of AQP1 in extracellular water transport by silencing the gene expression of AQP1, and to assist in elucidating the mechanism of impaired alveolar fluid clearance in lung edema. As A549 cells and AEC-II share similar structure 
and function (27), in the present study A549 cells were used as they multiply more rapidly and are easy to obtain, rather than pulmonary epithelial cells.

RNAi refers to the phenomenon of specific degradation of homologous mRNA, resulting from exogenous or endogenous small double-stranded RNA and subsequent post-transcriptional gene silencing in an organism (28). RNAi as a novel gene disruption technique, which has become an important tool in investigating gene function due to its advantages, including high specificity, high efficacy, high stability and low toxicity (29).

In the present study, the extracellular to intracellular fluid transportation capacity was attenuated following AQP1-silencing, as the cell volume was reduced in the transfection group exposed to air and hyperoxia, compared with that in the negative control group at $72 \mathrm{~h}$. Reduced osmotic water permeability and impaired water transport function following AQP1 gene silencing were also observed. In addition, the Pf values were reduced in the gene silencing group, compared with the negative control group at 48 and $72 \mathrm{~h}$, in exposure to air or hyperoxia. These results indicated that AQP1 is important in fluid transport in A549 cells. Combined with the findings of previous studies, these changes may be correlated with the downregulation of AQP1 induced by hyperoxia, and weakened fluid transportation function $(5,18)$. Therefore, the downregulation of AQP1 induced by hyperoxia in A549 cells impaired the fluid transportation function of the cell membrane and reduced alveolar fluid clearance, which may be one of the important causal factors responsible for lung edema during the acute phase of hyperoxic lung injury.

\section{Acknowledgements}

The authors would like to thank the Experimental Center of China Medical University Affiliated Shengjing Hospital for the guidance and assistance provided. The present study was supported by the National Natural Science Foundation of China (grant no. 30872781) and the Scientific Research Fund of the First Affiliated Hospital of Harbin Medical University (grant no. 2013B18).

\section{References}

1. Chang LW: Part of China's urban premature incidence of bronchial pulmonary dysplasia and risk factors. The 9th national neonatal meeting, 2009

2. Qi QY, Chen W, Li XL, Wang YW and Xie XH: $\mathrm{H}_{2}$ S protecting against lung injury following limb ischemia-reperfusion by alleviating inflammation and water transport abnormality in rats. Biomed Environ Sci 27: 410-418, 2014.

3. Elias AS, Oliveira GP, Ornellas DS, Morales MM, Capelozzi VL, Haddad R, Pelosi P, Rocco PR and Garcia CS: Effects of early and late pneumothorax drainage on the development of pulmonary oedema. Respir Physiol Neurobiol 195: 27-36, 2014.

4. Wang Q, Ishikawa T, Michiue T, Zhu BL, Guan DW and Maeda H: Molecular pathology of pulmonary edema after injury in forensic autopsy cases. Int J Legal Med 126: 875-882, 2012.

5. Zhang QY, Fu JH and Xue XD: Expression and function of aquaporin-1 in hyperoxia-exposed alveolar epithelial type II cells. Exp Ther Med 8: 493-498, 2014.

6. Lecuona E, Trejo HE and Sznajder JI: Regulation of Na, K-ATPase during acute lung injury. J Bioenerg Biomembr 39: 391-395, 2007

7. Winer J, Jung CK, Shackel I and Williams PM: Development and validation of real-time quantitative reverse transcriptasepolymerase chain reaction for monitoring gene expression in cardiac myocytes in vitro. Anal Biochem 270: 41-49, 1999.
8. Jordan CT, Yamasaki G and Minamoto D: High-resolution cell cycle analysis of defined phenotypic subsets within primitive human hematopoietic cell populations. Exp Hematol 24: 1347-1355, 1996.

9. Preston GM, Carroll TP, Guggino WB and Agre P: Appearance of water channels in Xenopus oocytes expressing red cell CHIP28 protein. Science 256: 385-387, 1992.

10. Verkman AS: Physiological importance of aquaporin water channels. Ann Med 34: 192-200, 2002.

11. Itoh T, Rai T, Kuwahara M, Ko SB, Uchida S, Sasaki S and Ishibashi K: Identification of a novel aquaporin, AQP12, expressed in pancreatic acinar cells. Biochem Biophys Res Commun 330: 832-838, 2005.

12. Borok Z and Verkman AS: Lung edema clearance: 20 years of progress: Invited review: Role of aquaporin water channls in fluid transport in lung and airways. J Appl Physiol (1985) 93: 2199-2206, 2002.

13. Jiao GY, Li ER and Yu R: Decreased expression of AQP1 and AQP5 in acute injured lungs in rats. Chin Med J (Engl) 155: 963-967, 2002.

14. Towne JE, Harrod KS, Krane CM and Menon AG: Decreased expression of aquaporin (AQP)1 and AQP5 in mouse lung after acute viral infection. Am J Respir Cell Mol Biol 22: 34-44, 2000.

15. Matthay MA, Folkesson HG and Clerici C: Lung epithelial fluid transport and the resolution of pulmonary edema. Physiol Rev 82: 569-600, 2002.

16. Krane CM, Deng B, Mutyam V, McDonald CA, Pazdziorko S, Mason L, Goldman S, Kasaian M, Chaudhary D, Williams C and Ho MW: Altered regulation of aquaporin gene expression in allergen and IL-13-induced mouse models of asthma. Cytokine 46: 111-118, 2009.

17. Wang F, Huang H, Lu F and Chen Y: Acute lung injury and change in expression of aquaporins 1 and 5 in a rat model of acute pancreatitis. Hepatogastroenterology 57: 1553-1562, 2010.

18. Wu XM, Wang HY, Li GF, Zang B and Chen WM: Dobutamine enhances alveolar fluid clearance in a rat model of acute lung injury. Lung 187: 225-231, 2009.

19. Jin LD, Wang LR, Wu LQ, Shan YL, Zhao XY, Xiong XQ, Zhou JH, Lin LN and Jin LL: Effects of COX-2 inhibitor on ventilator-induced lung injury in rats. Int Immunopharmacol 16: 288-295, 2013

20. Gao Z, Xu J, Sun D, Zhang R, Liang R, Wang L and Fan R: Traditional Chinese medicine, Qing Ying Tang, ameliorates the severity of acute lung injury induced by severe acute pancreatitis in rats via the upregulation of aquaporin-1. Exp Ther Med 8: 1819-1824, 2014.

21. Song Y, Ma T, Mathay MA and Verkman AS: Role of aquaporin-4 in airspace-to-capillary water permeability in intact mouse lung measured by a novel gravimetric method. J Gen Physol 155: 17-27, 2000.

22. King LS, Nielsen S, Agre P and Brown RH: Decreased pulmonary vascular permeability in aquaporin-1-null humans. Proc Natl Acad Sci USA 99: 1059-1063, 2002.

23. Li J, Xu M, Fan Q, Xie X, Zhang Y, Mu D, Zhao P, Zhang B, Cao F, Wang Y, et al: Tanshinone IIA ameliorates seawater exposure-induced lung injury by inhibiting aquaporins (AQP) 1 and AQP5 expression in lung. Respir Physiol Neurobiol 176: 39-49, 2011.

24. Lai KN, Leung JC, Metz CN, Lai FM, Bucala R and Lan HY: Role for macrophage migration inhibitory factor in acute respiratory distress syndrome. J Pathol 199: 496-508, 2003.

25. Song Y, Fukuda N, Bai C, Ma T, Matthay MA and Verkman AS: Role of aquaporins in alveolar fluid clearance in neonatal and adult lung and in oedema formation following acute lung injury: Studies in transgenic aquaporin null mice. J Physiol 525: 771-779, 2000.

26. Modi N: Clinical implications of postnatal alterations in body water distribution. Semin Neonatol 8: 301-306, 2003.

27. Chen F, Zhang C, Jia X, Wang S, Wang J, Chen Y, Zhao J, Tian S, Han X and Han L: Transcriptome profiles of human lung epithelial cells A549 interacting with aspergillus fumigatus by RNA-Seq. PLoS One 10: e0135720, 2015.

28. Fire A, Xu S, Montgomery MK, Kostas SA, Driver SE and Mello CC: Potent and spectific genetic interference by double-stranded RNA in Caenorhabditis elegans. Nature 391: 806-811, 1998.

29. Aagaard L and Rossi JJ: RNAi therapeutics: Principles, prospects and chanllenges. Adv Drug Deliv Rev 59: 75-86, 2007. 